\title{
Resurgence of SARS-CoV-2: detection by community viral surveillance
}

\author{
Steven Riley ${ }^{1,2 *}$, Kylie E. C. Ainsliee, ${ }^{1,2}$ Oliver Eales ${ }^{1,2}$, Caroline E. Walters ${ }^{1,2}$, Haowei Wang',2, \\ Christina Atchison', Claudio Fronterre ${ }^{3,4}$, Peter J. Diggle ${ }^{3,4}$, Deborah Ashby', Christl A. Donnelly ${ }^{1,2,5}$, \\ Graham Cooke $^{6,7,8}$, Wendy Barclay ${ }^{6}$, Helen Ward ${ }^{1,7,8}$, Ara Darzi ${ }^{7,8,9}$, Paul Elliott ${ }^{1,7,8,10 *}$
}

${ }^{1}$ School of Public Health, Imperial College London, London, UK. ${ }^{2}$ MRC Centre for Global Infectious Disease Analysis and Abdul Latif Jameel Institute for Disease and Emergency Analytics, Imperial College London, London, UK. ${ }^{3}$ Centre for Health Informatics, Computing, and Statistics (CHICAS), Lancaster Medical School, Lancaster University, Lancaster, UK. ${ }^{4}$ Health Data Research UK, London, UK. ${ }^{5}$ Department of Statistics, University of Oxford, Oxford, UK. ${ }^{6}$ Department of Infectious Disease, Imperial College London, London, UK. ${ }^{7}$ Imperial College Healthcare NHS Trust, London, UK. ${ }^{8}$ National Institute for Health Research Imperial Biomedical Research Centre, London, UK. ${ }^{9}$ Institute of Global Health Innovation, Imperial College London, London, UK. ${ }^{10} \mathrm{MRC}$ Centre for Environment and Health, School of Public Health, Imperial College London, London, UK.

${ }^{*}$ Corresponding author. Email: s.riley@imperial.ac.uk (S.R.); p.elliott@imperial.ac.uk (P.E.)

Surveillance of the SARS-CoV-2 epidemic has mainly relied on case reporting which is biased by health service performance, test availability and test-seeking behaviors. We report a community-wide national representative surveillance program in England involving self-administered swab results from 594,000 individuals tested for SARS-CoV-2, regardless of symptoms, from May to beginning of September 2020. The epidemic declined between May and July 2020 but then increased gradually from mid-August, accelerating into early September 2020 at the start of the second wave. When compared to cases detected through routine surveillance, we report here a longer period of decline and a younger age distribution. Representative community sampling for SARS-CoV-2 can substantially improve situational awareness and feed into the public health response even at low prevalence.

Prior to widespread rollout of effective vaccines (1-3), SARSCoV-2 infection continues to cause substantial COVID-19 morbidity and mortality globally (4). As variants with potentially increased transmissibility emerge (5), populations around the world continue to trade-off between social interactions and risk of infection (6). However, reduced social contact (7) has adverse effects on levels of economic activity (8), non-COVID-19 related health, and overall well-being (9). The ability of both individuals and governments to continue to balance these competing demands requires accurate and timely knowledge of the spread of the virus in the population so that informed choices about interventions can be made.

Data streams based on respiratory symptoms, such as those used for COVID-19 surveillance in most countries are prone to biases that can obscure underlying trends, such as variations in test availability and test-seeking behavior (10). Some countries have augmented these systems with surveys of virus prevalence in the wider population, but these have mostly been one-off activities, for example, in Wuhan, China (11), or were designed explicitly as interventions, for example, in Slovakia (12). Here we show results from the REal-time Assessment of Community Transmission-1 (REACT-1) study, a representative community-wide program that is tracking prevalence of SARS-CoV-2 virus across England through repeated random population-based sampling (13). It was designed to rapidly detect resurgence of SARS-CoV-2 transmission, including at low prevalence, thus providing early warning of any upturn in infections to feed into the policy response and enable timely implementation of public health interventions.

Over four rounds from 1 May to 8 September 2020, we invited 2.4 million people to join the study, from whom we obtained 596,000 tested swabs (Table 1) for an overall response rate of $25 \%$ (table S1). Between round 1 (1 May to 1 June 2020) and round 2 (19 June to 7 July) there was a fall in weighted prevalence from $0.16 \%$ (95\% confidence interval, $0.12 \%, 0.19 \%)$ to $0.088 \%(0.068 \%, 0.11 \%)$ (Table 1 and Fig. 1 ). Infections fell further to their lowest observed value in round 3 (24 July to 11 August) with 54 positive samples out of 161,560 swabs, giving a weighted prevalence of $0.040 \%$ $(0.027 \%, 0.053 \%)$. This compares to a 100 -fold higher prevalence of $\sim 5 \%$ at the peak of the first UK wave, based on the daily incidence of infection for the UK greater than 300,000 (14), and with the assumption that individuals would test swab-positive for $\sim 10$ days on average (15). Prevalence then increased in round 4 (22 August to 8 September), where we 
found 137 positive samples out of 154,325 swabs, giving a weighted prevalence of $0.13 \%(0.10 \%, 0.15 \%)$.

Using a model of constant exponential growth and decay (16), we quantified this fall and rise in prevalence in terms of halving and doubling times and reproduction number $\mathrm{R}$ (Fig. 1 and Table 2). Over rounds 2 and 3 (19 June to 11 August) prevalence fell with an estimated halving time of 27 (95\% credible intervals, 20,42) days corresponding to an $\mathrm{R}$ value of $0.85(0.79,0.90)$. Prevalence then increased over rounds 3 and 4 (24. July to 8 September) with a doubling time of 17 (14, 23) days corresponding to an $\mathrm{R}$ value of 1.28 (1.20, 1.36). Our estimates of $\mathrm{R}$ and doubling times were similar in sensitivity analyses among nonsymptomatic people [average $72 \%$ (95\% confidence interval, $67 \%, 76 \%)]$ or those positive for both $\mathrm{E}$ gene and $\mathrm{N}$ gene (table $\mathrm{S} 2$ ).

We compared epidemic trends estimated from REACT-1 data above with those based on routine surveillance data (Fig. 1, figs. S1 and S2, and Table 2) over the same period. Numbers of routine surveillance cases were growing from start round 2 to end round 3 (19 June to 11 August) with a corresponding $\mathrm{R}$ of 1.05 (1.02, 1.07) (Table 2) when swab-positivity was declining in REACT-1. R estimates from routine surveillance data were likely biased upwards because there was a neardoubling of test capacity during this period (17) (fig. S1). These findings are consistent with experience in the UK during the 2009 influenza pandemic when there was substantial temporal variations in the sensitivity of case-based PCR surveillance (18).

We also observed an apparent shift from decline to growth using within-round data (fig. S3 and Table 2). During round 3 (24 July to 11 August), with 94\% probability, the epidemic had started to grow with a doubling time of 14 days (95\% credible interval from halving every 59 days to doubling every 6.4 days), corresponding to an $\mathrm{R}$ of 1.34 (0.93, 1.83) (Fig. 1 and Table 1). During round 4 (22 August to 8 September), the doubling time reduced to $8.0(5.7,14)$ days, with $\mathrm{R}$ of 1.64 (1.35, 1.95). In response to the rapidly increasing epidemic the UK government announced a more stringent social distancing measure, the "rule of six" (19).

We relaxed our assumption of constant growth or decay using a flexible p-spline (16) (fig. S1) and inferred a plateau or slight increase in prevalence in July 2020 in the gap between rounds 2 and 3 . As a result, the prevalence for round 3 started higher than expected from the data observed at the end of round 2, a pattern similar to that seen in data from the Office for National Statistics Coronavirus (COVID-19) Infection Survey pilot (20). Using the p-spline, we estimated that lowest prevalence occurred on 20 July (13 July, 15 August) (fig. S3) compared with 5 July (30 June, 16 July) estimated from the routine surveillance data, likely reflecting the rapid increase in testing capacity (fig. S3).

During March and April, the highest prevalence regionally was recorded in London, which experienced the highest incidence of cases during the first wave $(21,22)$. Prevalence fell in all regions between round 1 ( 1 May to 1 June) and round 3 (24 July to 4 August). There was then positive growth (>95\% probability) between round 3 and round 4 (20 August to 8 September) in all regions except East and West Midlands (table S3 and figs. S4 and S5), with highest growth in the North East region [R 1.67 (1.20, 2.48)]. During round 4 (22 August to 8 September) we observed a $\sim 3$-fold difference between the highest prevalence in both North West at $0.17 \%$ $(0.12 \%, 0.24 \%)$ and Yorkshire and The Humber at $0.17 \%$ $(0.11 \%, 0.27 \%)$, and the lowest at $0.06 \%(0.04 \%, 0.09 \%)$ in the South East (Fig. 2, table S4, and fig. S4).

We found spatial heterogeneity in prevalence at sub-regional level using a geospatial model (16) with range parameter estimate 22.6 (95\% confidence interval, 16.1, 31.7) km (Fig. 3 and table S5). We observed areas of higher prevalence in parts of the North West region, Yorkshire and The Humber, Midlands and the London conurbation in round 1 (1 May to 1 June). These patterns persisted at lower prevalence in round 2 (19 June to 7 July) before reaching lowest prevalence in round 3 (24 July to 11 August). The epidemic then resurged in round 4 (20 August to 8 September) with geographical patterns similar to those seen in rounds 1 and 2 , and an indication that prevalence in each local area had increased between rounds 3 and 4 (fig. S5).

Our findings show substantial variations in age patterns over time. In round 4 (22 August to 8 September), highest prevalence at $0.25 \%(0.16 \%, 0.41 \%)$ was found in participants aged 18 to 24 years, increasing more than 3 -fold from $0.08 \%$ $(0.04 \%, 0.18 \%)$ in round 3 (24 July to 11 August) (Fig. 2 and table S4). The lowest prevalence was in those aged 65 years and older at $0.04 \%(0.02 \%, 0.06 \%)$, similar to round 3 . These patterns suggest that the second wave started in young adults-likely driven by higher numbers of social contacts (23)-before spreading into older $(22,24)$ and more at-risk populations (25).

We compared age patterns from REACT- 1 with those in the routine surveillance case incidence data (17); in each dataset we estimated odds ratios for each age group (35 to 44 years as comparator, fig. S6). We found that the symptomatic case data in round 1 (1 May to 1 June) overestimated odds at older ages and underestimated odds at younger ages relative to REACT-1, reflecting the limited availability of symptomatic testing at that time when testing was carried out mainly among hospitalized patients (17). In subsequent rounds, the case data consistently underestimated odds at ages 5 to 14 years while odds at older ages continued to be overestimated relative to REACT-1. Similar biases in case data may have contributed to reports of reduced susceptibility to infection in younger children (26).

We found differences over time in the odds of infection 
for health care and care home workers, with odds of 5.5 (3.1, 9.7) relative to other workers during round 1 (1 May to 1 June) but much reduced odds in subsequent rounds (table S6). These findings indicate that there was a shift away from rapid transmission in hospitals (27) and care homes (28) during the first wave to predominantly community transmission at the start of the second wave.

We found a $\sim 2$-fold greater unweighted prevalence of swab-positivity in participants of Asian ethnicity (mainly south Asian) at $0.14 \%(0.10 \%, 0.20 \%)$ compared with $0.07 \%$ $(0.07 \%, 0.08 \%)$ in white participants across all four rounds combined (table S4); odds were $2.2(1.2,4.0)$ relative to white participants in round 4 (20 August to 8 September), with multiple adjustment (table S6). There was also a higher unadjusted prevalence of infection in Black people compared to white people across all four rounds combined at $0.15 \%$ $(0.09 \%, 0.27 \%)$ (table S4). These higher rates of swab-positivity are consistent with higher SARS-CoV-2 seroprevalence among people of Asian, Black and other ethnicities in England (22). This supports the view that higher rates of hospitalization and mortality from COVID-19 reported amongst minority ethnic groups in England (29) reflect their higher rates of infection rather than a poorer prognosis once infected.

Although we aimed to be representative of the population of England by inviting a random sample of people on the National Health Service patient register (16), we found differential response rates by age, area and round. For example, response rates ranged from $21.8 \%$ in round 4 (20 August to 8 September) to $30.8 \%$ in round 1 ( 1 May to 1 June) and across age groups from $10.7 \%$ at ages 18 to 24 years to $31.1 \%$ at 55 to 64 years (round 4). However, unlike the symptomatic testing, we were able to correct for variations in response since we have a known denominator. We were thus able to estimate prevalence weighted to the population of England as a whole, taking into account sample design and nonresponse, although we did not re-weight prevalence estimates for subgroups because of lower numbers of positives.

We converted growth rates into reproduction numbers using serial interval parameters from (30). However, we also tested the sensitivity of our results to a wide range of other published estimates (table S7). We found that by using (30) our estimates of $\mathrm{R}$ above 1 were conservative and using other published parameters lowered our R estimates. The converse was true for $\mathrm{R}$ values below 1 : estimates using (30) were lower than those using results from other studies. Essentially, uncertainty in our estimates of $\mathrm{R}$ reflect uncertainty in our estimate of the growth rate and do not propagate uncertainty about the serial interval present in the literature.

We relied on self-swabbing to obtain estimates of swab positivity. A throat and nose swab is estimated to have $\sim 70 \%$ to $\sim 80 \%$ sensitivity (31), so we are likely to have underestimated true prevalence, although this would be unlikely to have affected trend analyses or estimation of R. During the period of our study, there was changing availability of symptom-driven test capacity which likely explains the earlier increase in swab-positivity in the symptomatic data compared with our own data (17). The trends in our data were supported by results of analyses among the subset of nonsymptomatic individuals, who would not have presented to the national case testing program (table S2).

Our study provides timely community-based prevalence data to increase situational awareness and inform the public health response during the current SARS-CoV-2 pandemic. The scenario of declining prevalence to low levels followed by resurgence reported here may reoccur in the future in the absence of protective population immunity; this depends on levels of vaccine coverage of the population (32), degree of waning of natural immunity and vaccine efficacy (33), and potential for antigenic escape (34). Also, as of early 2021, some populations have successfully avoided large waves of infection but may not be able to do so in the future because of intervention fatigue or increased transmissibility of the virus (35).

Accurate estimates of prevalence with robust descriptions of trends by time, person and place would support sustainable policies designed to maintain low levels of prevalence. Unlike China, New Zealand and Australia, the UK did not attempt functional elimination (COVID-zero) during periods of low prevalence in February or August 2020, in common with all other European nations. However, with the roll-out of effective vaccines from December 2020 (36) and with accumulating evidence of antigenic change (37), the cost-benefit assessment of policies designed to achieve sustained low levels of prevalence may be different in the future. For example, during the declining phase, prevalence may be high in some areas because of low vaccine uptake, variant emergence or increased social mixing. Data from REACT-1 or similar studies could be used to target local public health or vaccination campaigns more effectively than would be possible with routine surveillance data alone, similar to how REACT-1 results fed into the government policy of the rule of six in early September 2020 (19).

Additionally, knowledge from community-based surveillance can be used to calibrate other data streams - not only symptomatic testing (38)-but also the use of mobility data (39) and sewage-based sampling of viral RNA (40). Given the different spatial and temporal resolutions of alternate data sources, ground-truth data such as those from REACT-1 can substantially improve evidence synthesis for infectious disease (41).

We demonstrate the capability of a large national community surveillance program to detect a resurgence of SARSCoV-2 infection at low prevalence. Our findings have 
implications for policies to contain the COVID-19 pandemic. While we wait for the vaccination of all risk groups in England and across the world, control of the SARS-CoV-2 virus must continue to rely on established public health measures (42) including social distancing, frequent hand-washing, face covers and an effective test, trace and isolate system. Although we show high levels of effectiveness of stringent social distancing during the first lockdown in England, prevalence subsequently increased. This perhaps reflects holiday travel, return to work, or a more general increase in the number and transmission potential of social interactions, with a rapid rise evident in early September 2020 at the start of the second wave. A combination of vaccination, social distancing and other public health measures should again result in substantial reductions in prevalence. Studies similar to REACT-1 could then detect any upturn in prevalence and help trigger an effective public health response.

\section{REFERENCES AND NOTES}

1. E. J. Anderson, N. G. Rouphael, A. T. Widge, L. A. Jackson, P. C. Roberts, M. Makhene, J. D. Chappell, M. R. Denison, L. J. Stevens, A. J. Pruijssers, A. B. McDermott, B. Flach, B. C. Lin, N. A. Doria-Rose, S. O'Dell, S. D. Schmidt, K. S. Corbett, P. A. Swanson 2nd, M. Padilla, K. M. Neuzil, H. Bennett, B. Leav, M. Makowski, J. Albert, K. Cross, V. V. Edara, K. Floyd, M. S. Suthar, D. R. Martinez, R. Baric, W. Buchanan, C. J. Luke, V. K. Phadke, C. A. Rostad, J. E. Ledgerwood, B. S. Graham, J. H. Beigel; mRNA-1273 Study Group, Safety and immunogenicity of SARS-CoV-2 mRNA1273 vaccine in older adults. N. Engl. J. Med. 383, 2427-2438 (2020). doi:10.1056/NEJMoa2028436 Medline

2. M. Voysey, S. A. C. Clemens, S. A. Madhi, L. Y. Weckx, P. M. Folegatti, P. K. Aley, B. Angus, V. L. Baillie, S. L. Barnabas, Q. E. Bhorat, S. Bibi, C. Briner, P. Cicconi, A. M. Collins, R. Colin-Jones, C. L. Cutland, T. C. Darton, K. Dheda, C. J. A. Duncan, K. R. W. Emary, K. J. Ewer, L. Fairlie, S. N. Faust, S. Feng, D. M. Ferreira, A. Finn, A. L. Goodman, C. M. Green, C. A. Green, P. T. Heath, C. Hill, H. Hill, I. Hirsch, S. H. C. Hodgson, A. Izu, S. Jackson, D. Jenkin, C. C. D. Joe, S. Kerridge, A. Koen, G. Kwatra, R. Lazarus, A. M. Lawrie, A. Lelliott, V. Libri, P. J. Lillie, R. Mallory, A. V. A. Mendes, E. P. Milan, A. M. Minassian, A. McGregor, H. Morrison, Y. F. Mujadidi, A. Nana, P. J. O'Reilly, S. D. Padayachee, A. Pittella, E. Plested, K. M. Pollock, M. N. Ramasamy, S. Rhead, A. V. Schwarzbold, N. Singh, A. Smith, R. Song, M. D. Snape, E. Sprinz, R. K. Sutherland, R. Tarrant, E. C. Thomson, M. E. Török, M. Toshner, D. P. J. Turner, J. Vekemans, T. L. Villafana, M. E. E. Watson, C. J. Williams, A. D. Douglas, A. V. S. Hill, T. Lambe, S. C. Gilbert, A. J. Pollard; Oxford COVID Vaccine Trial Group, Safety and efficacy of the ChAdOx1 nCoV-19 vaccine (AZD1222) against SARS-CoV-2: An interim analysis of four randomised controlled trials in Brazil, South Africa, and the UK. Lancet 397, 99-111 (2021). doi:10.1016/S01406736(20)32661-1 Medline

3. F. P. Polack, S. J. Thomas, N. Kitchin, J. Absalon, A. Gurtman, S. Lockhart, J. L. Perez, G. Pérez Marc, E. D. Moreira, C. Zerbini, R. Bailey, K. A. Swanson, S. Roychoudhury, K. Koury, P. Li, W. V. Kalina, D. Cooper, R. W. Frenck Jr., L. L. Hammitt, Ö. Türeci, H. Nell, A. Schaefer, S. Ünal, D. B. Tresnan, S. Mather, P. R. Dormitzer, U. Şahin, K. U. Jansen, W. C. Gruber; C4591001 Clinical Trial Group, Safety and efficacy of the BNT162b2 mRNA Covid-19 vaccine. N. Engl. J. Med. 383, 2603-2615 (2020). doi:10.1056/NEJMoa2034577 Medline

4. Johns Hopkins University, Coronavirus Resource Center; https://coronavirus.jhu.edu/.

5. Public Health England, New SARS-CoV-2 variant: Information on the new variants of the SARS-CoV-2 virus, www.gov.uk; www.gov.uk/government/collections/new-sars-cov-2-variant.

6. J. Zhang, M. Litvinova, Y. Liang, Y. Wang, W. Wang, S. Zhao, Q. Wu, S. Merler, C. Viboud, A. Vespignani, M. Ajelli, H. Yu, Changes in contact patterns shape the dynamics of the COVID-19 outbreak in China. Science 368, 1481-1486 (2020). doi:10.1126/science.abb8001 Medline

7. C. I. Jarvis, K. Van Zandvoort, A. Gimma, K. Prem, P. Klepac, G. J. Rubin, W. J. Edmunds; CMMID COVID-19 working group, Quantifying the impact of physical distance measures on the transmission of COVID-19 in the UK. BMC Med. 18, 124 (2020). doi:10.1186/s12916-020-01597-8 Medline

8. S. Luo, K. P. Tsang, China and world output impact of the Hubei lockdown during the coronavirus outbreak. Contemp. Econ. Policy 38, 583-592 (2020). doi:10.1111/coep.12482 Medline

9. R. Layard, A. Clark, J. De Neve, C. Krekel, D. Fancourt, N. Hey, G. O'Donnell, When to release the lockdown? A wellbeing framework for analysing costs and benefits, IZA Discussion Paper No. 13186, SSRN (2020); https://ssrn.com/abstract $=3590884$

10. R. Moss, A. E. Zarebski, S. J. Carlson, J. M. McCaw, Accounting for healthcareseeking behaviours and testing practices in real-time influenza forecasts. Trop Med Infect Dis 4, 12 (2019). doi:10.3390/tropicalmed4010012 Medline

11. S. Cao, Y. Gan, C. Wang, M. Bachmann, S. Wei, J. Gong, Y. Huang, T. Wang, L. Li, K. Lu, H. Jiang, Y. Gong, H. Xu, X. Shen, Q. Tian, C. Lv, F. Song, X. Yin, Z. Lu, Postlockdown SARS-CoV-2 nucleic acid screening in nearly ten million residents of Wuhan, China. Nat. Commun. 11, 5917 (2020). doi:10.1038/s41467-020-19802-w Medline

12. M. Pavelka, K. Van-Zandvoort, S. Abbott, K. Sherratt, M. Majdan, I. Z. Analýz, P. Jarčuška, M. Krajčí, S. Flasche, S. Funk; CMMID COVID-19 working group, The impact of population-wide rapid antigen testing on SARS-CoV-2 prevalence in Slovakia. Science eabf9648 (2021). doi:10.1126/science.abf9648 Medline

13. S. Riley, C. Atchison, D. Ashby, C. A. Donnelly, W. Barclay, G. Cooke, H. Ward, A. Darzi, P. Elliott, REACT study group, REal-time Assessment of Community Transmission (REACT) of SARS-CoV-2 virus: Study protocol. Wellcome Open Res. 5, 200 (2020). doi:10.12688/wellcomeopenres.16228.1

14. S. Flaxman, S. Mishra, A. Gandy, H. J. T. Unwin, T. A. Mellan, H. Coupland, C. Whittaker, H. Zhu, T. Berah, J. W. Eaton, M. Monod, A. C. Ghani, C. A. Donnelly, S. Riley, M. A. C. Vollmer, N. M. Ferguson, L. C. Okell, S. Bhatt; Imperial College COVID-19 Response Team, Estimating the effects of non-pharmaceutical interventions on COVID-19 in Europe. Nature 584, 257-261 (2020). 10.1038/s41586-020-2405-7 Medline

15. L. M. Kucirka, S. A. Lauer, O. Laeyendecker, D. Boon, J. Lessler, Variation in falsenegative rate of reverse transcriptase polymerase chain reaction-based SARSCoV-2 tests by time since exposure. Ann. Intern. Med. 173, 262-267 (2020). doi:10.7326/M20-1495 Medline

16. Materials and methods are available as supplementary materials.

17. UK Government, Coronavirus (COVID-19) in the UK dashboard, www.gov.uk; https://coronavirus. data.gov.uk/.

18. I. Dorigatti, S. Cauchemez, N. M. Ferguson, Increased transmissibility explains the third wave of infection by the 2009 H1N1 pandemic virus in England. Proc. Natl. Acad. Sci. U.S.A. 110, 13422-13427 (2013). doi:10.1073/pnas.1303117110 Medline

19. Home Office, Rt Hon Priti Patel MP, "Rule of six comes into effect to tackle coronavirus," $\quad$ www.gov.uk, 14 September 2020; www.gov.uk/government/news/rule-of-six-comes-into-effect-to-tacklecoronavirus.

20. Office for National Statistics, "Coronavirus (COVID-19) Infection Survey pilot: England, 9 July 2020," 9 July 2020; www.ons.gov.uk/releases/coronaviruscovid19infectionsurveypilotengland9july2 $\underline{020}$.

21. Office for National Statistics, "Deaths registered weekly in England and Wales, provisional: week ending 4 September 2020," 15 September 2020; www.ons.gov.uk/releases/deathsregisteredinenglandandwalesprovisionalweek ending 4 september2020.

22. H. Ward, C. J. Atchison, M. Whitaker, K. E. C. Ainslie, J. Elliott, L. C. Okell, R. Redd, D. Ashby, C. A. Donnelly, W. Barclay, A. Darzi, G. Cooke, S. Riley, P. Elliott, SARSCoV-2 antibody prevalence in England following the first peak of the pandemic. Nat. Commun. 12, 905 (2021). doi:10.1038/s41467-021-21237-w Medline

23. J. Mossong, N. Hens, M. Jit, P. Beutels, K. Auranen, R. Mikolajczyk, M. Massari, S. Salmaso, G. S. Tomba, J. Wallinga, J. Heijne, M. Sadkowska-Todys, M. Rosinska, W. J. Edmunds, Social contacts and mixing patterns relevant to the spread of infectious diseases. PLOS Med. 5, e74 (2008). 
doi:10.1371/journal.pmed.0050074 Medline

24. Office for National Statistics, "Coronavirus (COVID-19) Infection Survey, UK: 8 January 2021," 8 January 2021; www.ons.gov.uk/releases/coronaviruscovid19infectionsurveyuk.

25. R. Verity, L. C. Okell, I. Dorigatti, P. Winskill, C. Whittaker, N. Imai, G. CuomoDannenburg, H. Thompson, P. G. T. Walker, H. Fu, A. Dighe, J. T. Griffin, M. Baguelin, S. Bhatia, A. Boonyasiri, A. Cori, Z. Cucunubá, R. FitzJohn, K. Gaythorpe, W. Green, A. Hamlet, W. Hinsley, D. Laydon, G. Nedjati-Gilani, S. Riley, S. van Elsland, E. Volz, H. Wang, Y. Wang, X. Xi, C. A. Donnelly, A. C. Ghani, N. M. Ferguson, Estimates of the severity of coronavirus disease 2019: A model-based analysis. Lancet Infect. Dis. 20, 669-677 (2020). doi:10.1016/S14733099(20)30243-7 Medline

26. N. G. Davies, P. Klepac, Y. Liu, K. Prem, M. Jit, R. M. Eggo; CMMID COVID-19 working group, Age-dependent effects in the transmission and control of COVID19 epidemics. Nat. Med. 26, 1205-1211 (2020). doi:10.1038/s41591-020-0962-9 Medline

27. L. Rivett, S. Sridhar, D. Sparkes, M. Routledge, N. K. Jones, S. Forrest, J. Young, J. Pereira-Dias, W. L. Hamilton, M. Ferris, M. E. Torok, L. Meredith, M. D. Curran, S. Fuller, A. Chaudhry, A. Shaw, R. J. Samworth, J. R. Bradley, G. Dougan, K. G. Smith, P. J. Lehner, N. J. Matheson, G. Wright, I. G. Goodfellow, S. Baker, M. P. Weekes; CITIID-NIHR COVID-19 BioResource Collaboration, Screening of healthcare workers for SARS-CoV-2 highlights the role of asymptomatic carriage in COVID19 transmission. eLife 9, e58728 (2020). doi:10.7554/eLife.58728 Medline

28. N. S. N. Graham, C. Junghans, R. Downes, C. Sendall, H. Lai, A. McKirdy, P. Elliott, R. Howard, D. Wingfield, M. Priestman, M. Ciechonska, L. Cameron, M. Storch, M. A. Crone, P. S. Freemont, P. Randell, R. McLaren, N. Lang, S. Ladhani, F. Sanderson, D. J. Sharp, SARS-CoV-2 infection, clinical features and outcome of COVID-19 in United Kingdom nursing homes. J. Infect. 81, 411-419 (2020). doi:10.1016/i.jinf.2020.05.073 Medline

29. Office for National Statistics, "Coronavirus (COVID-19) related deaths by ethnic group, England and Wales: 2 March 2020 to 10 April 2020," 7 May 2020; www.ons.gov.uk/releases/coronavirusrelateddeathsbyethnicgroupenglandand wales2march2020to10april2020.

30. Q. Bi, Y. Wu, S. Mei, C. Ye, X. Zou, Z. Zhang, X. Liu, L. Wei, S. A. Truelove, T. Zhang, W. Gao, C. Cheng, X. Tang, X. Wu, Y. Wu, B. Sun, S. Huang, Y. Sun, J. Zhang, T. Ma, J. Lessler, T. Feng, Epidemiology and transmission of COVID-19 in 391 cases and 1286 of their close contacts in Shenzhen, China: A retrospective cohort study. Lancet Infect. Dis. 20, 911-919 (2020). doi:10.1016/S1473-3099(20)30287-5 Medline

31. B. Böger, M. M. Fachi, R. O. Vilhena, A. F. Cobre, F. S. Tonin, R. Pontarolo, Systematic review with meta-analysis of the accuracy of diagnostic tests for COVID-19. Am. J. Infect. Control 49, 21-29 (2021). doi:10.1016/i.ajic.2020.07.011 Medline

32. P. Peretti-Watel, V. Seror, S. Cortaredona, O. Launay, J. Raude, P. Verger, L. Fressard, F. Beck, S. Legleye, O. L'Haridon, D. Léger, J. K. Ward; COCONEL Group, A future vaccination campaign against COVID-19 at risk of vaccine hesitancy and politicisation. Lancet Infect. Dis. 20, 769-770 (2020). doi:10.1016/S14733099(20)30426-6 Medline

33. M. Jeyanathan, S. Afkhami, F. Smaill, M. S. Miller, B. D. Lichty, Z. Xing, Immunological considerations for COVID-19 vaccine strategies. Nat. Rev. Immunol. 20, 615-632 (2020). doi:10.1038/s41577-020-00434-6 Medline

34. C. K. Wibmer, F. Ayres, T. Hermanus, M. Madzivhandila, P. Kgagudi, B. Oosthuysen, B. E. Lambson, T. de Oliveira, M. Vermeulen, K. van der Berg, T. Rossouw, M. Boswell, V. Ueckermann, S. Meiring, A. von Gottberg, C. Cohen, L. Morris, J. N. Bhiman, P. L. Moore, SARS-CoV-2 501Y.V2 escapes neutralization by South African COVID-19 donor plasma. Nat. Med. 27, 622-625 (2021). doi:10.1038/s41591-021-01285-x Medline

35. J. Wise, Covid-19: New coronavirus variant is identified in UK. BMJ 371, m4857 (2020). doi:10.1136/bmi.m4857 Medline

36. E. Mahase, Covid-19: UK approves Pfizer and BioNTech vaccine with rollout due to start next week. BMJ 371, m4714 (2020). doi:10.1136/bmi.m4714 Medline

37. A. J. Greaney, A. N. Loes, K. H. D. Crawford, T. N. Starr, K. D. Malone, H. Y. Chu, J. D. Bloom, Comprehensive mapping of mutations in the SARS-CoV-2 receptorbinding domain that affect recognition by polyclonal human plasma antibodies. Cell Host Microbe 29, 463-476.e6 (2021). doi:10.1016/j.chom.2021.02.003
Medline

38. D. A. Drew, L. H. Nguyen, C. J. Steves, C. Menni, M. Freydin, T. Varsavsky, C. H. Sudre, M. J. Cardoso, S. Ourselin, J. Wolf, T. D. Spector, A. T. Chan; COPE Consortium, Rapid implementation of mobile technology for real-time epidemiology of COVID-19. Science 368, 1362-1367 (2020). doi:10.1126/science.abc0473 Medline

39. B. Jeffrey, C. E. Walters, K. E. C. Ainslie, O. Eales, C. Ciavarella, S. Bhatia, S. Hayes, M. Baguelin, A. Boonyasiri, N. F. Brazeau, G. Cuomo-Dannenburg, R. G. FitzJohn, K. Gaythorpe, W. Green, N. Imai, T. A. Mellan, S. Mishra, P. Nouvellet, H. J. T. Unwin, R. Verity, M. Vollmer, C. Whittaker, N. M. Ferguson, C. A. Donnelly, S. Riley, Anonymised and aggregated crowd level mobility data from mobile phones suggests that initial compliance with COVID-19 social distancing interventions was high and geographically consistent across the UK. Wellcome Open Res. 5, 170 (2020). doi:10.12688/wellcomeopenres.15997.1 Medline

40. I. Bar-Or, K. Yaniv, M. Shagan, E. Ozer, O. Erster, E. Mendelson, B. Mannasse, R. Shirazi, E. Kramarsky-Winter, O. Nir, H. Abu-Ali, Z. Ronen, E. Rinott, Y. E. Lewis, E. Friedler, E. Bitkover, Y. Paitan, Y. Berchenko, A. Kushmaro, Regressing SARSCoV-2 sewage measurements onto COVID-19 burden in the population: A proofof-concept for quantitative environmental surveillance. medRxiv 2020.04.26.20073569 [Preprint]. 1 May 2020. https://doi.org/10.1101/2020.04.26.20073569.

41. E. van Leeuwen, P. Klepac, D. Thorrington, R. Pebody, M. Baguelin, fluEvidenceSynthesis: An R package for evidence synthesis based analysis of epidemiological outbreaks. PLOS Comput. Biol. 13, e1005838 (2017). doi:10.1371/journal.pcbi.1005838 Medline

42. Cabinet Office, "Coronavirus (COVID-19): What has changed - 9 September," www.gov.uk, 9 September 2020; www.gov.uk/government/news/coronaviruscovid-19-what-has-changed-9-september

43. S. Riley, O. Eales, C. E. Walters, H. Wang, K. E. C. Ainslie, C. Atchison, C. Fronterre, P. J. Diggle, D. Ashby, C. A. Donnelly, G. Cooke, W. Barclay, H. Ward, A. Darzi, P. Elliott, reactidd $\mathrm{R}$ package with data, Version 0.91, Zenodo (2021); http://doi.org/10.5281/zenodo.4681283.

44. M. D. Hoffman, A. Gelman, The No-U-Turn Sampler: Adaptively Setting Path Lengths in Hamiltonian Monte Carlo. arXiv:1111.4246 [stat.CO] (18 November 2011).

45. J. Wallinga, M. Lipsitch, How generation intervals shape the relationship between growth rates and reproductive numbers. Proc. Biol. Sci. 274, 599-604 (2007). doi:10.1098/rspb.2006.3754 Medline

46. S. Lang, A. Brezger, Bayesian P-Splines. J. Comput. Graph. Stat. 13, 183-212 (2004). doi:10.1198/1061860043010

47. P. J. Diggle, E. Giorgi, Model-based Geostatistics for Global Public Health (CRC Press, 2019)

48. E. Giorgi, P. J. Diggle, Others, PrevMap: An R package for prevalence mapping. J. Stat. Softw. 78, 1-29 (2017). doi:10.18637/iss.v078.108

49. T. Sharot, Weighting survey results. J. Mar. Res. Soc. 28, 269-284 (1986).

50. Office for National Statistics, "Population estimates for the UK, England and Wales, Scotland and Northern Ireland: mid-2019," 24 June 2020; www.ons.gov.uk/peoplepopulationandcommunity/populationandmigration/pop ulationestimates/bulletins/annualmidyearpopulationestimates/mid2019estima tes.

51. Office for National Statistics, "Annual Population Survey/Labour Force Survey"; www.nomisweb.co.uk/sources/aps.

52. T. Lumley, Analysis of complex survey samples. J. Stat. Softw. 9, 1-19 (2004). doi:10.18637/iss.v009.j08

\section{ACKNOWLEDGMENTS}

We thank key collaborators on this work-Ipsos MORI: K. Beaver, S. Clemens, G. Welch, A. Cleary, K. Ward and K. Pickering; Institute of Global Health Innovation at Imperial College: G. Fontana, S. Satkunarajah and L. Naar; MRC Centre for Environment and Health, Imperial College London: D. Fecht; Molecular Diagnostic Unit, Imperial College London: G. Taylor; North West London Pathology and Public Health England for help in calibration of the laboratory analyses; NHS Digital for access to the NHS register; and the Department of Health and Social Care for logistic support. S.R. acknowledges helpful discussion with members of the UK Government Office for Science (GO-Science) Scientific 
Pandemic Influenza - Modelling (SPI-M) committee. Ethics: We obtained research ethics approval from the South Central-Berkshire B Research Ethics Committee (IRAS ID: 283787). Funding: This research was funded by the Department of Health and Social Care in England. S.R. and C.A.D. acknowledge support: MRC Centre for Global Infectious Disease Analysis, National Institute for Health Research (NIHR) Health Protection Research Unit (HPRU), Wellcome Trust (200861/Z/16/Z, 200187/Z/15/Z), and Centres for Disease Control and Prevention (US, U01CK0005-01-02). G.C. is supported by an NIHR Professorship. P.E. is Director of the MRC Centre for Environment and Health (MR/L01341X/1, MR/S019669/1) and receives support from the NIHR Imperial Biomedical Research Centre and the NIHR HPRUs in Chemical and Radiation Threats and Hazards and Environmental Exposures and Health, the British Heart Foundation Centre for Research Excellence at Imperial College London (RE/18/4/34215), the UK Dementia Research Institute at Imperial (MC_PC_17114) and Health Data Research UK (HDR UK). We thank The Huo Family Foundation for their support of our work on COVID-19. Author contributions: S.R. and P.E. conceptualized and designed the study and drafted the manuscript. S.R., K.E.C.A., O.E., Ha.W., C.F. and C.E.W. undertook the data analysis. P.J.D., D.A. and C.A.D. provided statistical advice. G.C., W.B., H.W., C.A. and A.D. provided study oversight. A.D. and P.E. obtained funding. S.R., K.E.C.A., O.E., Ha.W., C.E.W., C.A., P.J.D., D.A., C.A.D., G.C., W.B., H.W., G.T., A.D. and P.E. critically reviewed the manuscript. All authors read and approved the final version of the manuscript. P.E. is the guarantor for this paper. The corresponding author attests that all listed authors meet authorship criteria and that no others meeting the criteria have been omitted, had full access to all the data in the study, and had final responsibility for the decision to submit for publication. Competing interests: The authors declare no competing interests. Data and materials availability: Code and additional data to support the figures are freely available (43). This work is licensed under a Creative Commons Attribution 4.0 International (CC BY 4.0) license, which permits unrestricted use, distribution, and reproduction in any medium, provided the original work is properly cited. To view a copy of this license, visit

https://creativecommons,org/licenses/by/4.0/. This license does not apply to figures/photos/artwork or other content included in the article that is credited to a third party; obtain authorization from the rights holder before using such material.

\section{SUPPLEMENTARY MATERIALS}

science.sciencemag.org/cgi/content/full/science.abf0874/DC1

Materials and Methods

Figs. S1 to 56

Tables S1 to S7

References (44-52)

MDAR Reproducibility Checklist

Data S1

5 October 2020; accepted 20 April 2021

Published online 23 April 2021

10.1126/science.abf0874 
Table 1. Unweighted and weighted prevalence of swab-positivity across seven rounds of REACT-1.

\begin{tabular}{|c|c|c|c|c|}
\hline Round & 1 & 2 & 3 & 4 \\
\hline First sample & $1 / 5 / 2020$ & $19 / 6 / 2020$ & $24 / 7 / 2020$ & $20 / 8 / 2020$ \\
\hline Last sample & $1 / 6 / 2020$ & $7 / 7 / 2020$ & $11 / 8 / 2020$ & $8 / 9 / 2020$ \\
\hline Recruitment letters sent & 395,000 & 600,000 & 710,000 & 710,000 \\
\hline Swabs sent & 161,497 & 219,633 & 225,615 & 211,291 \\
\hline Tested swabs & 120,620 & 159,199 & 161,560 & 154,325 \\
\hline Swab response rate & $75 \%$ & $72 \%$ & $72 \%$ & $73 \%$ \\
\hline Overall response rate & $31 \%$ & $27 \%$ & $23 \%$ & $22 \%$ \\
\hline Positive swabs & 159 & 123 & 54 & 137 \\
\hline $\begin{array}{l}\text { Unweighted prevalence } \\
(95 \% \mathrm{CI})\end{array}$ & $\begin{array}{c}0.132 \%(0.113 \% \\
0.154 \%)\end{array}$ & $\begin{array}{c}0.077 \%(0.065 \% \\
0.092 \%)\end{array}$ & $\begin{array}{c}0.033 \%(0.025 \% \\
0.043 \%)\end{array}$ & $\begin{array}{c}0.089 \%(0.075 \% \\
0.105 \%)\end{array}$ \\
\hline $\begin{array}{l}\text { Weighted prevalence } \\
(95 \% \mathrm{CI})\end{array}$ & $\begin{array}{c}0.156 \%(0.124 \% \\
0.188 \%)\end{array}$ & $\begin{array}{c}0.088 \%(0.068 \%, \\
0.109 \%)\end{array}$ & $\begin{array}{c}0.040 \%(0.027 \%, \\
0.053 \%)\end{array}$ & $\begin{array}{c}0.125 \%(0.096 \%, \\
0.154 \%)\end{array}$ \\
\hline
\end{tabular}


Table 2. Fitted growth rates, reproduction numbers and doubling times (95\% credible intervals) for SARS-CoV-2 swab positivity in England.

\begin{tabular}{|c|c|c|c|c|c|c|}
\hline Data & Round(s)* & $\begin{array}{c}\text { Number of } \\
\text { participants/ } \\
\text { cases }\end{array}$ & Growth rate r (1/days) & $P(r>0)$ & Reproduction number & $\begin{array}{c}\text { Doubling }(+) / \text { halving }(-) \\
\text { time (days) }\end{array}$ \\
\hline \multirow[t]{7}{*}{ REACT All } & 1 & 110,944 & $-0.077(-0.107,-0.046)$ & $<0.01$ & $0.57(0.44,0.73)$ & $-9.0(-6.5,-14.9)$ \\
\hline & 2 & 157,428 & $-0.089(-0.130,-0.032)$ & $<0.01$ & $0.52(0.36,0.81)$ & $-7.8(-5.3,-21.4)$ \\
\hline & 3 & 162,619 & $0.049(-0.012,0.109)$ & 0.94 & $1.34(0.93,1.83)$ & $14.2(-58.6,6.4)$ \\
\hline & 4 & 153,964 & $0.086(0.050,0.122)$ & $>0.99$ & $1.64(1.35,1.95)$ & $8.0(13.8,5.7)$ \\
\hline & 1 and 2 & 268,422 & $-0.018(-0.025,-0.012)$ & $<0.01$ & $0.89(0.85,0.92)$ & $-37.9(-28.0,-57.5)$ \\
\hline & 2 and 3 & 320,047 & $-0.025(-0.034,-0.017)$ & $<0.01$ & $0.85(0.79,0.90)$ & $-27.3(-20.1,-41.6)$ \\
\hline & 3 and 4 & 316,583 & $0.041(0.030,0.051)$ & $>0.99$ & $1.28(1.20,1.36)$ & $17.0(22.8,13.5)$ \\
\hline \multirow{7}{*}{$\begin{array}{l}\text { Routine } \\
\text { surveillance } \\
\text { data }\end{array}$} & 1 & 69,299 & $-0.034(-0.042,-0.027)$ & $<0.01$ & $0.80(0.75,0.84)$ & $-20.3(-16.7,-26.0)$ \\
\hline & 2 & 11,523 & $-0.018(-0.032,-0.004)$ & 0.01 & $0.89(0.81,0.97)$ & $-38.5(-21.9,-164.1)$ \\
\hline & 3 & 15,172 & $0.026(0.004,0.049)$ & 0.99 & $1.18(1.03,1.34)$ & $26.2(161.4,14.2)$ \\
\hline & 4 & 31,209 & $0.085(0.067,0.104)$ & $>0.99$ & $1.63(1.48,1.79)$ & $8.1(10.3,6.7)$ \\
\hline & 1 and 2 & 97,255 & $-0.029(-0.031,-0.027)$ & $<0.01$ & $0.82(0.81,0.84)$ & $-23.7(-22.0,-25.7)$ \\
\hline & 2 and 3 & 36,393 & $0.007(0.003,0.012)$ & $>0.99$ & $1.05(1.02,1.07)$ & $93.6(207.6,60.6)$ \\
\hline & 3 and 4 & 56,064 & $0.029(0.023,0.035)$ & $>0.99$ & $1.19(1.15,1.24)$ & $24.1(30.7,20.1)$ \\
\hline
\end{tabular}

*See Table 1 for start and end dates of rounds 


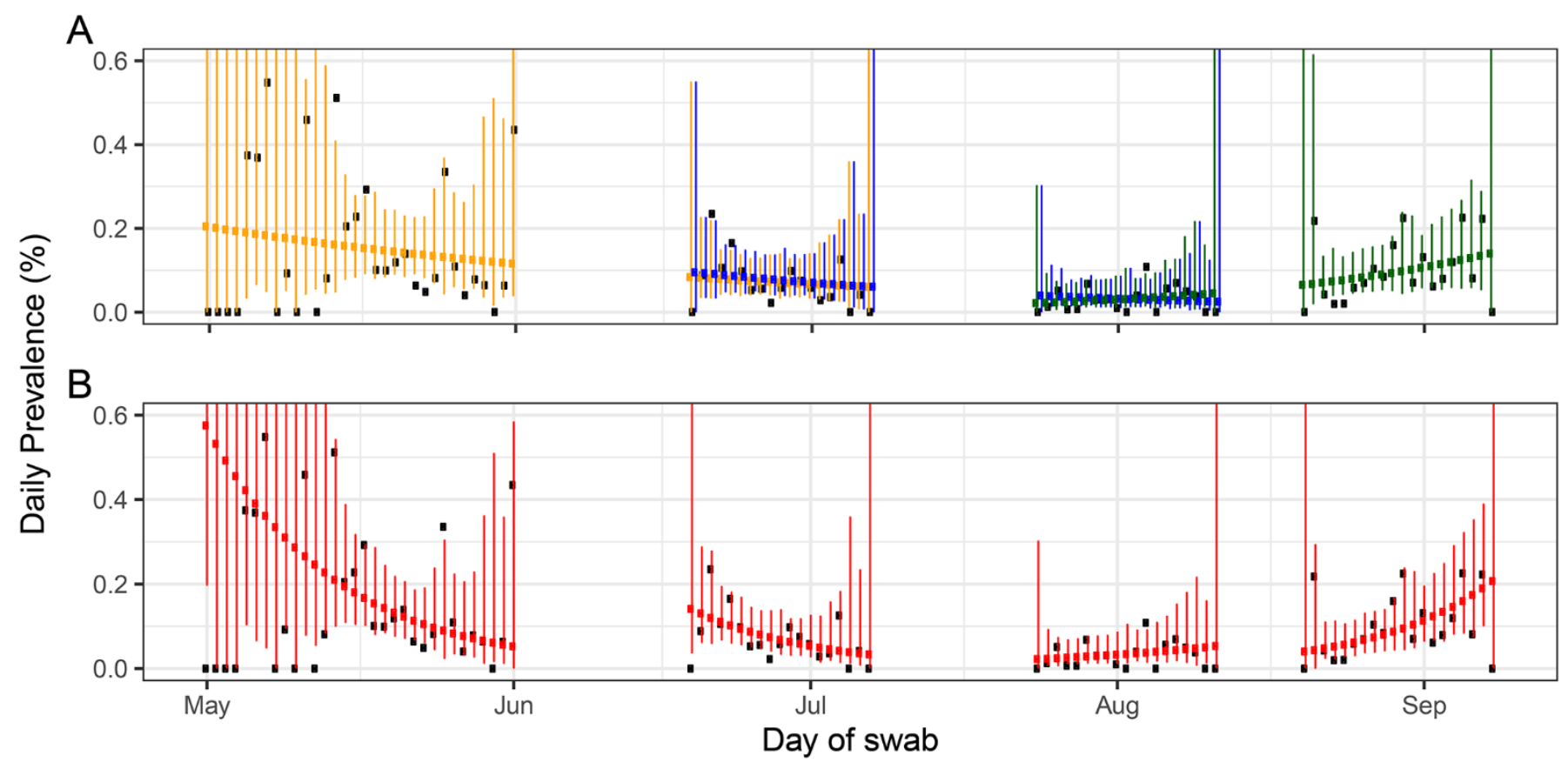

Fig. 1. Constant growth rate models fit to REACT-1 data for sequential and individual rounds. Model fits (A) to REACT-1 data for sequential rounds 1 and 2 (yellow), 2 and 3 (blue) and 3 and 4 (green). Vertical lines show $95 \%$ prediction intervals for models. Black points show observations. See Table 1 for $\mathrm{R}$ estimates. Models fit to individual rounds only (B) (red). Note only 585,004 of 596,965 tests had dates available and were included in the analysis ( 465 out of 473 positives were included). 

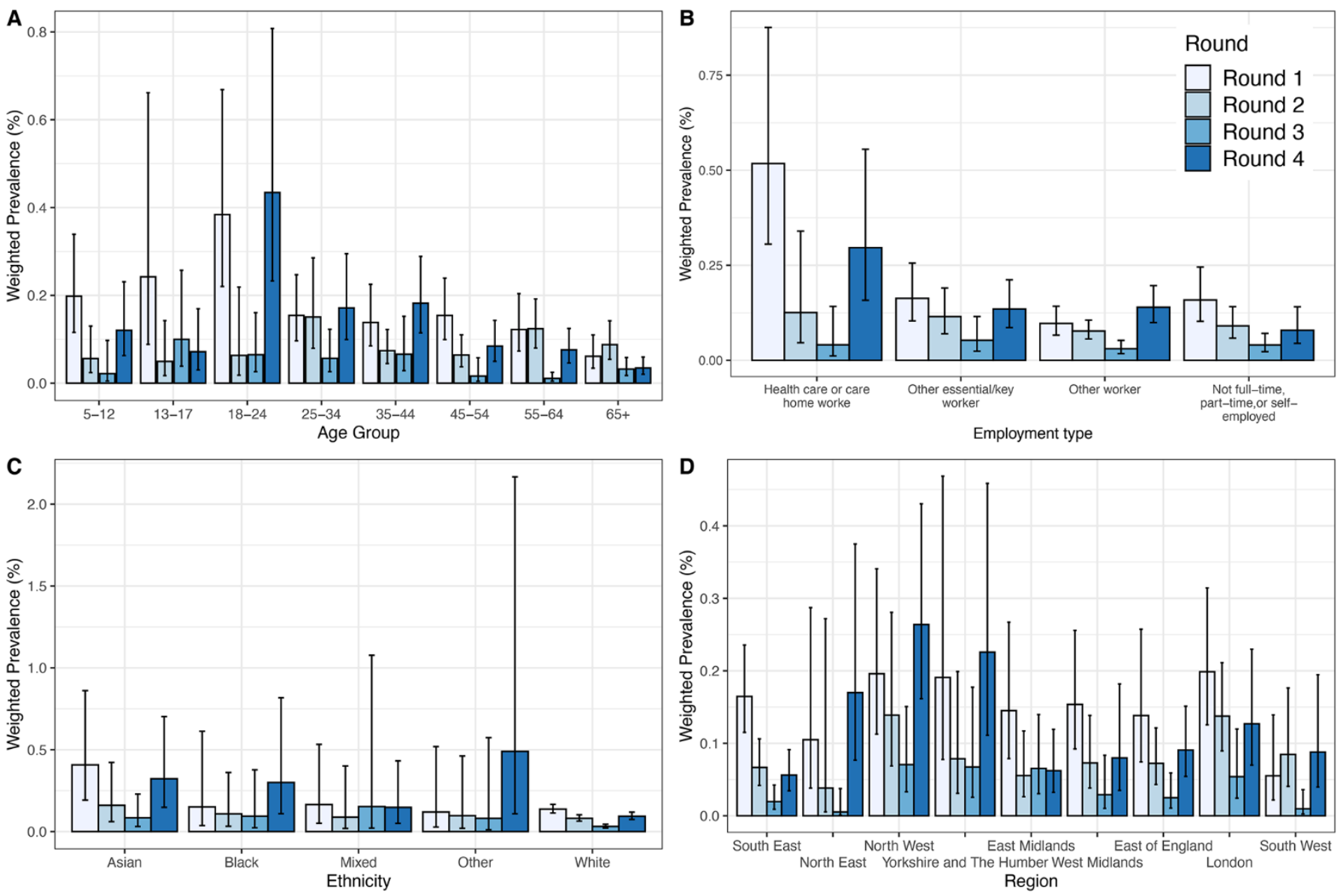

Fig. 2. Prevalence of unweighted swab-positivity. Covering four rounds of the REACT-1 study by age (A), employment type (B), ethnicity (C) and region (D). Vertical bars show 95\% confidence intervals. Rounds indicated in legend. 

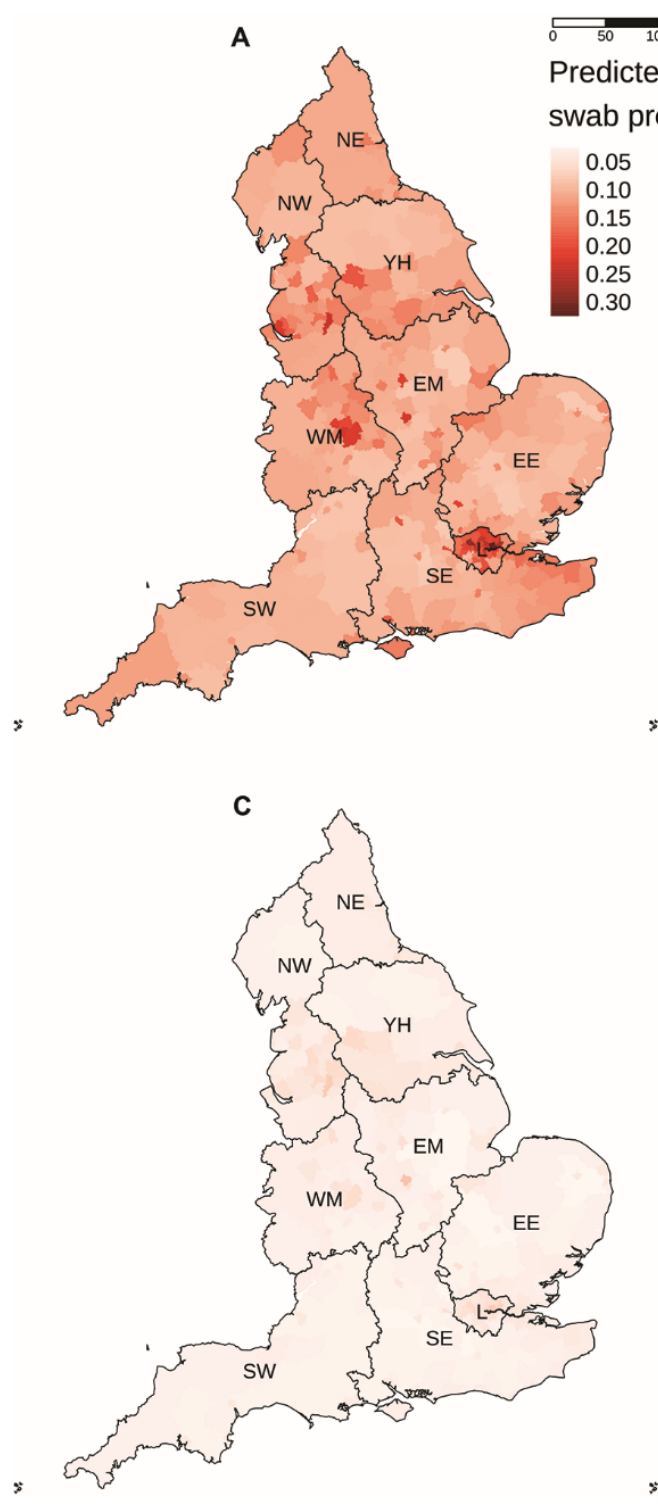

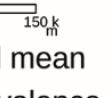

evalence (\%)

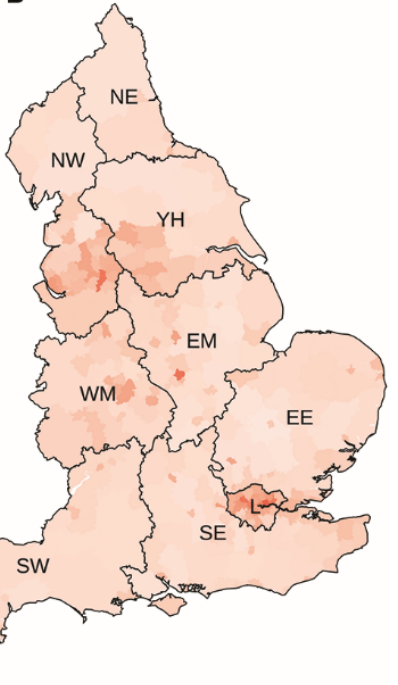

D

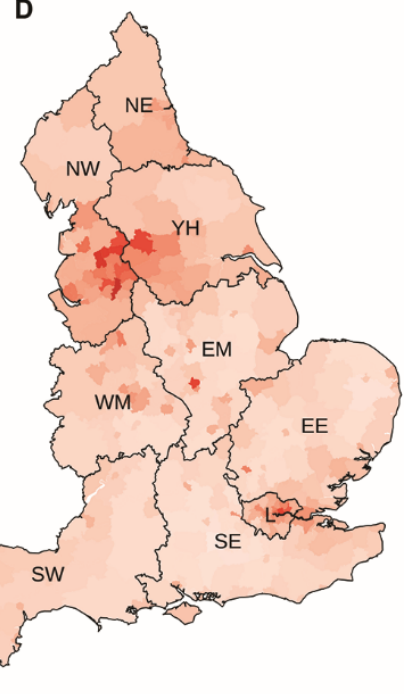

Fig. 3. Geospatial patterns. Estimated prevalence from geospatial model for $(A)$ round 1, (B) round 2, (C) round 3, and (D) round 4. Regions: NE = North East, NW $=$ North West, $\mathrm{YH}=$ Yorkshire and The Humber, EM = East Midlands, $\mathrm{WM}=$ West Midlands, $\mathrm{EE}=$ East of England, $\mathrm{L}=$ London, $\mathrm{SE}=$ South East, SW = South West. 